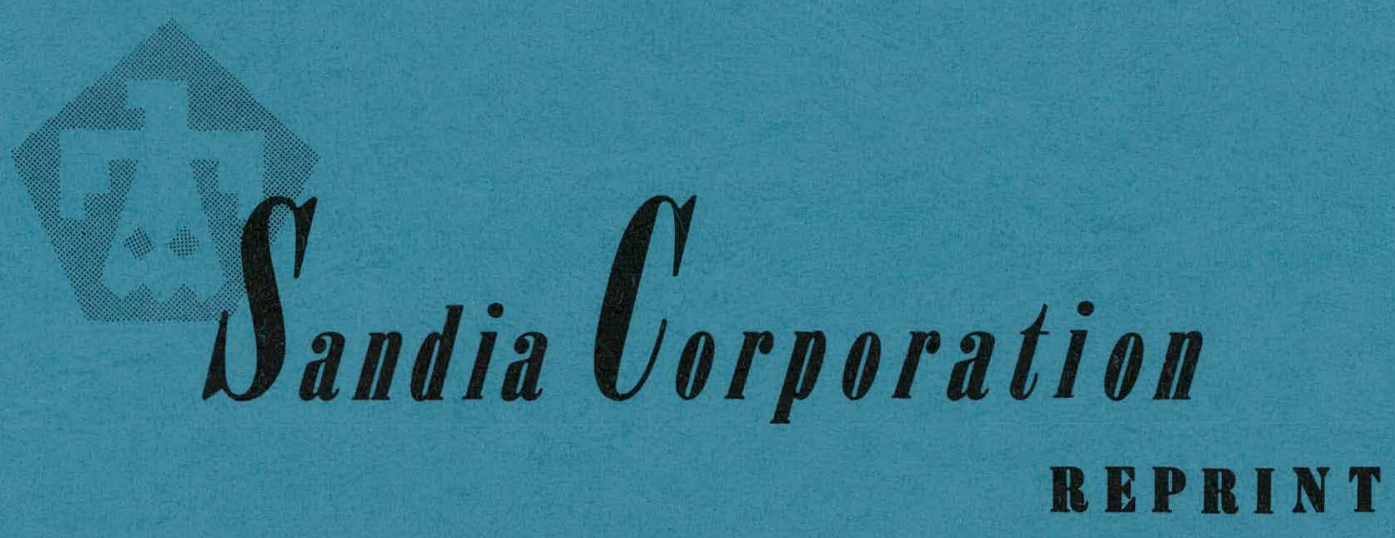

\title{
COMPARISON Of STAGnATIOO PRESSURE CONTROL SYSTEmS FOR A 12-InCH BLOWDOWn TRAnSOnIC tunnel
}

\author{
by \\ R.C.Maydew
}

June 1958 


\section{DISCLAIMER}

This report was prepared as an account of work sponsored by an agency of the United States Government. Neither the United States Government nor any agency Thereof, nor any of their employees, makes any warranty, express or implied, or assumes any legal liability or responsibility for the accuracy, completeness, or usefulness of any information, apparatus, product, or process disclosed, or represents that its use would not infringe privately owned rights. Reference herein to any specific commercial product, process, or service by trade name, trademark, manufacturer, or otherwise does not necessarily constitute or imply its endorsement, recommendation, or favoring by the United States Government or any agency thereof. The views and opinions of authors expressed herein do not necessarily state or reflect those of the United States Government or any agency thereof. 


\section{DISCLAIMER}

Portions of this document may be illegible in electronic image products. Images are produced from the best available original document. 
Presented at the Eighth Meeting of the SUPERSONIC WIND-TUNNEL ASSOCIATION

Seattle, Washington October 1957 


\title{
COMPARISON OF STAGNATION PRESSURE CONTROL SYSTEMS
}

FOR A 12-INCH BLOWDOWN TRANSONIC TUNNEL

\author{
R. C. MAYDEW, SANDIA CORPORATION
}

The tunnel exhausts to the atmosphere (12.2 psia) from a $2600 \mathrm{ft}^{3}$ storage tank at an initial pressure of $300 \mathrm{psig.} \mathrm{The} 12 \times 12$-inch transonic test section is a perforated type used in conjunction with a sonic nozzle. The Mach number range of 0.4 to 1.5 is obtained by varying stagnation pressure and/or test section wall angle, downstream ejector flap setting, diffuser choke-body setting and plenum by-pass valve opening. The tunnel mass flow varies from approximately 1 to 4 slugs/sec over the range of stagnation pressures from 13 to 42 psia. Run times on the order of 15 to 30 seconds are required for the pressure-distribution, free-oscillation dynamic-stability and three-component force tests conducted in this tunnel.

An elevation drawing of the tunnel is shown in the first slide. The air is discharged into the settling chamber through a quick-opening butterfly valve, a regulator valve and a wide angle diffuser. The storage pressure drops from 300 psig to approximately 100 psig during a typical mu. A rapid response pressure control system is necessary to minimize the starting transient and to maintain a constant stagnation pressure (or Mach number) during the data-gathering period.

The original control system installed is shown in the second slide. This system consists of a pilot controller, a multi-trol receiver controller, a three-way manual-to-automatic valve with respective pressure reducing valves and gages to each unit. Both controllers and the auto-control valve are supplied with 20 psig control air. The stagnation pressure pickup is located on the centerline of the settling chamber.

The output pressure from both controllers is 3 to 15 psig. The pilot controller has proportional band adjustment and the receiver controller has an adjustable set point, proportional band and reset rate adjustment. The automatic reset adjustment ( $15 \mathrm{sec}$. minimum) was disconnected from the system for obvious reasons.

Operation of this pneumatic controller is as follows:

1. The three-way valve is set for manual operation.

2. The auto-control valve is preset to position for the desired stagnation pressure.

3. The set point for the desired stagnation pressure for automatic operation is made with the preset to the receiver controller.

4. The butterfly valve is opened and the system is switched to automatic operation when the stagnation pressure builds up to the desired value. 
This system required use of a wideproportional band to prevent valve instability; this condition resulted in a gradual decay in stagnation pressure during a run.

The second control system (slide 3) installed consists of a differential pressure transmitter, a Tri-Act controller, two dual-pointer gages, two solenoid valves and precision loading regulator valves with associated gages. The pressure transmitter, the controller and the automatic control valve are supplied with 20 psig control air. The output pressure from the transmitter and the controller is 3 to 15 psig.

The Tri-Act control circuit consists of two stages with three pneumatic loops connected in series. The first stage has an adjustable proportional band with derivative action; the second stage employs a fixed proportional band and automatic reset. The loop sequence consists of a fixed proportional band with adjustable Pre-Act (derivative action) feeding an adjustable proportional band which actuates a loop containing a fixed proportional band with adjustable automatic reset. The controller settings used are a gain of $0.9 \mathrm{psi} / \mathrm{psi}$, an automatic reset of 2.5 repeats/second and a Pre-Act of 0.6 second.

Operation of this control system is as follows:

1. The solenoid valves are switched to manual operation (dashed lines in slide 3 ).

2. The auto-control valve is preset to position for the desired stagnation pressure by the 'upper center' precision loading regulator valve.

3. The reset chamber of the Tri-Act controller is preset to the same pressure as the auto-control valve (step 2) by the 'lower center' precision loading regulator valve.

4. The desired stagnation pressure is set into the Tri-Act controller with the 'lower right' precision loading regulator.

5. The butterfly valve is opened and the system is switched to automatic operation by energizing the solenoid valves when the stagnation pressure builds up to the desired value.

This control system has proven very satisfactory to date in that the starting transients have been reduced and the stagnation pressure is nearly constant during the data-gathering period. Measurements of valve travel have indicated this system will maintain a constant stagnation pressure until the regulator valve is fully open.

The two control systems are compared in slide 4 for nominal stagnation pressures of 16 and 34 psia. The improved performance of system B has resulted in increased Mach number capability of the tunnel, improved Mach number control during a run, and an increase in the run frequency. 


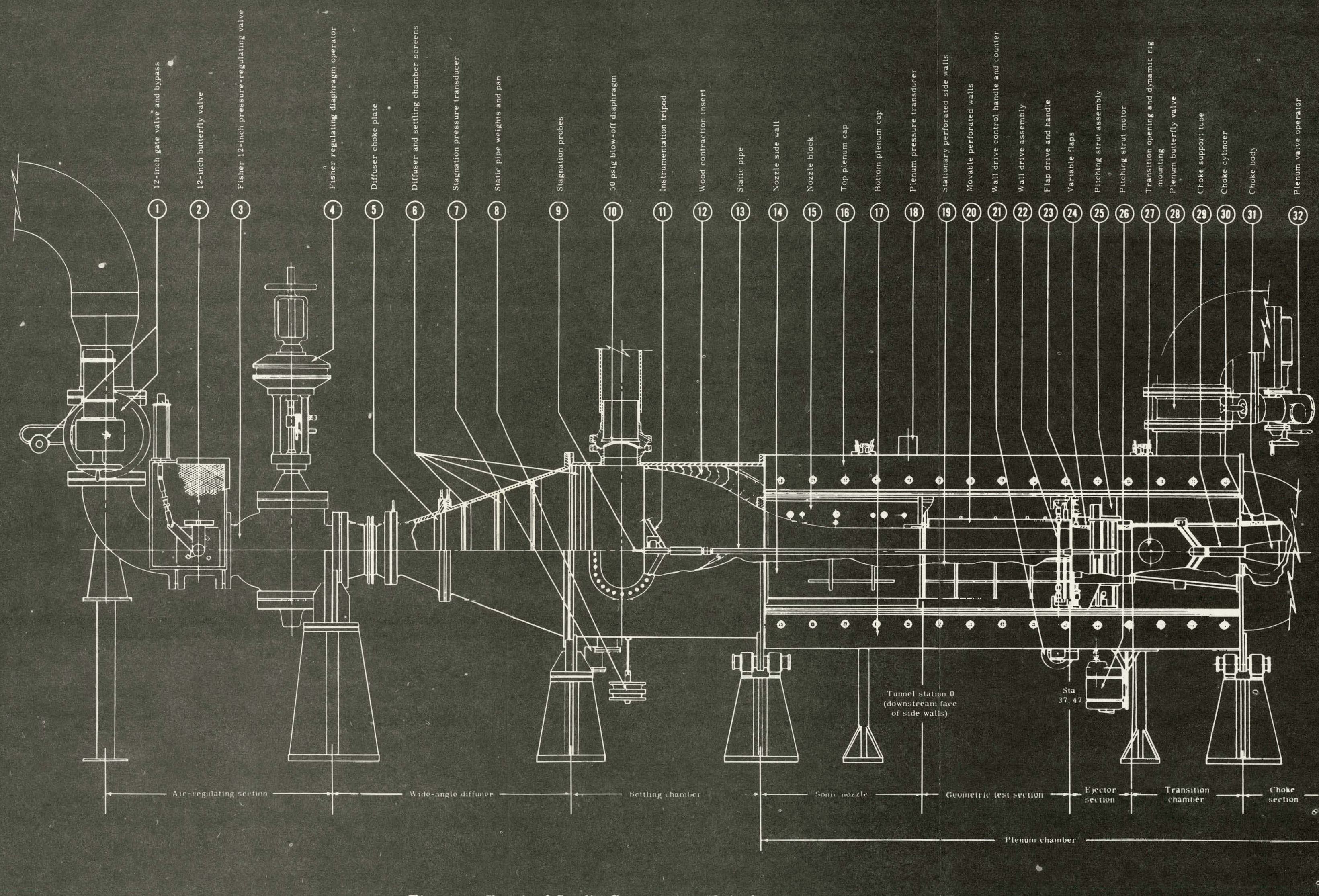

Fig. 1 -- Sketch of Sandia Corporation 12-inch transonic wind tunnel 


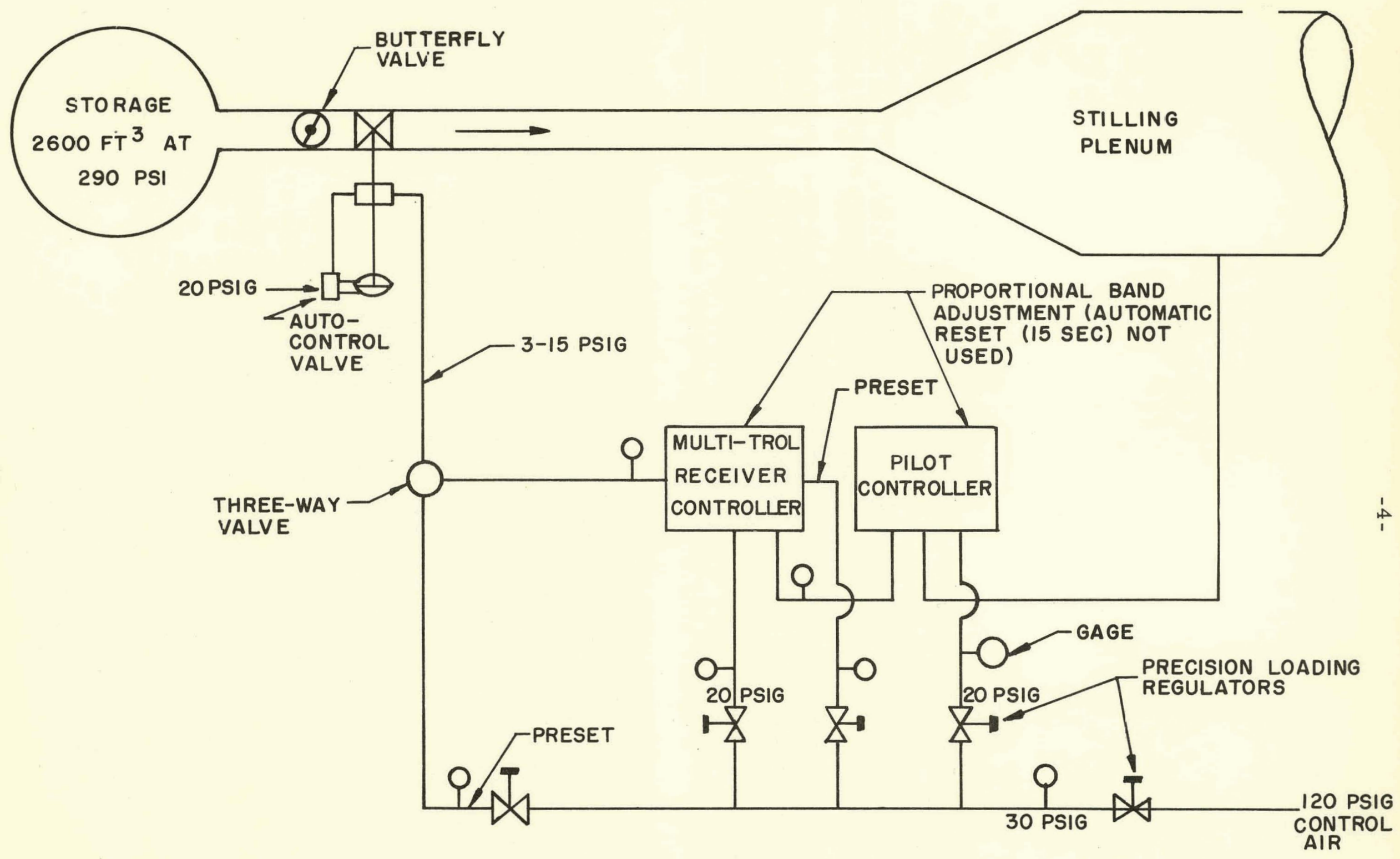

FIGURE - 2

SANDIA I2" BLOW DOWN WIND TUNNEL CONTROL SYSTEM "A" 


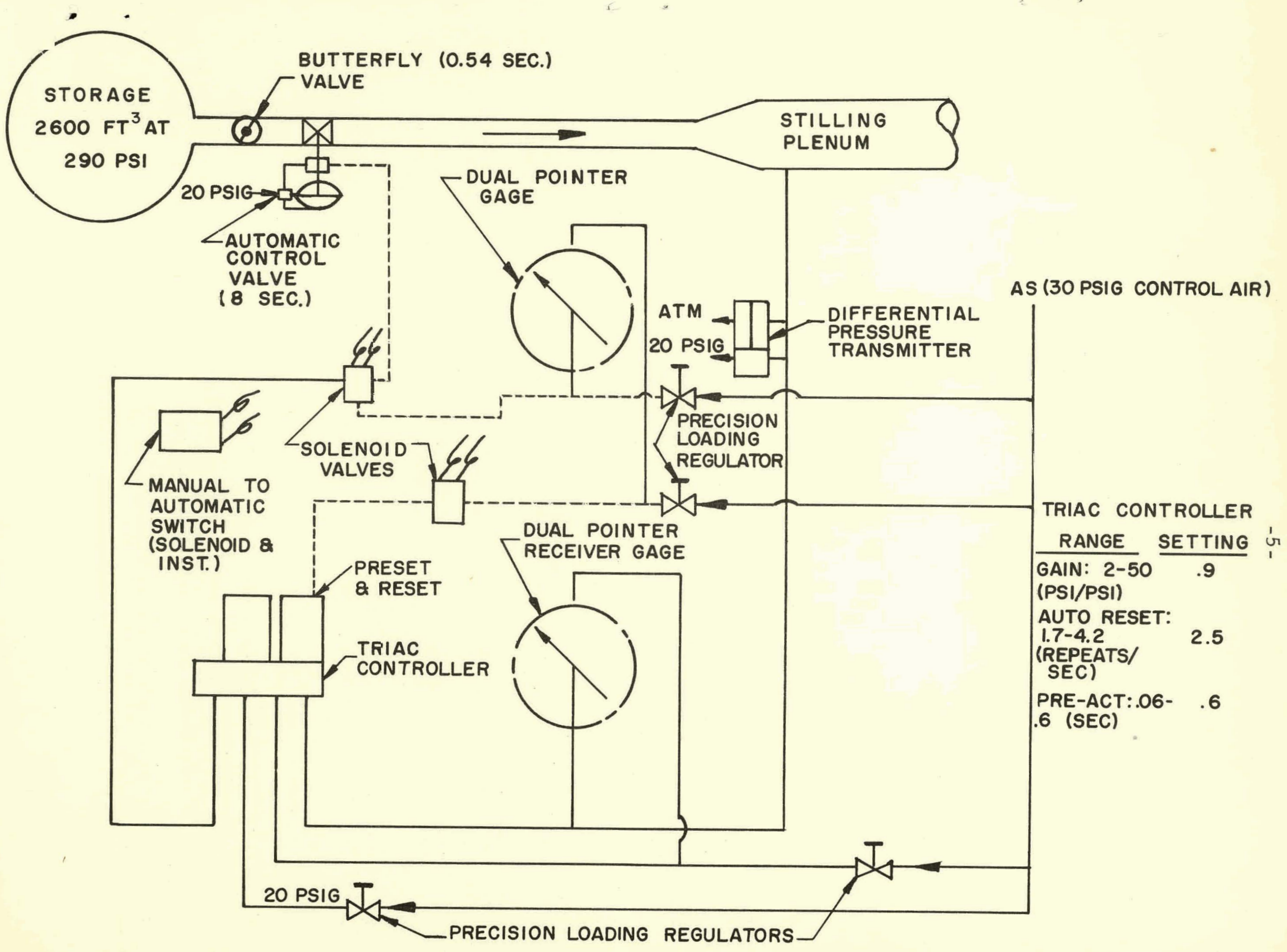

FIGURE - 3

SANDIA I2" BLOW DOWN WIND TUNNEL CONTROL SYSTEM "B" 


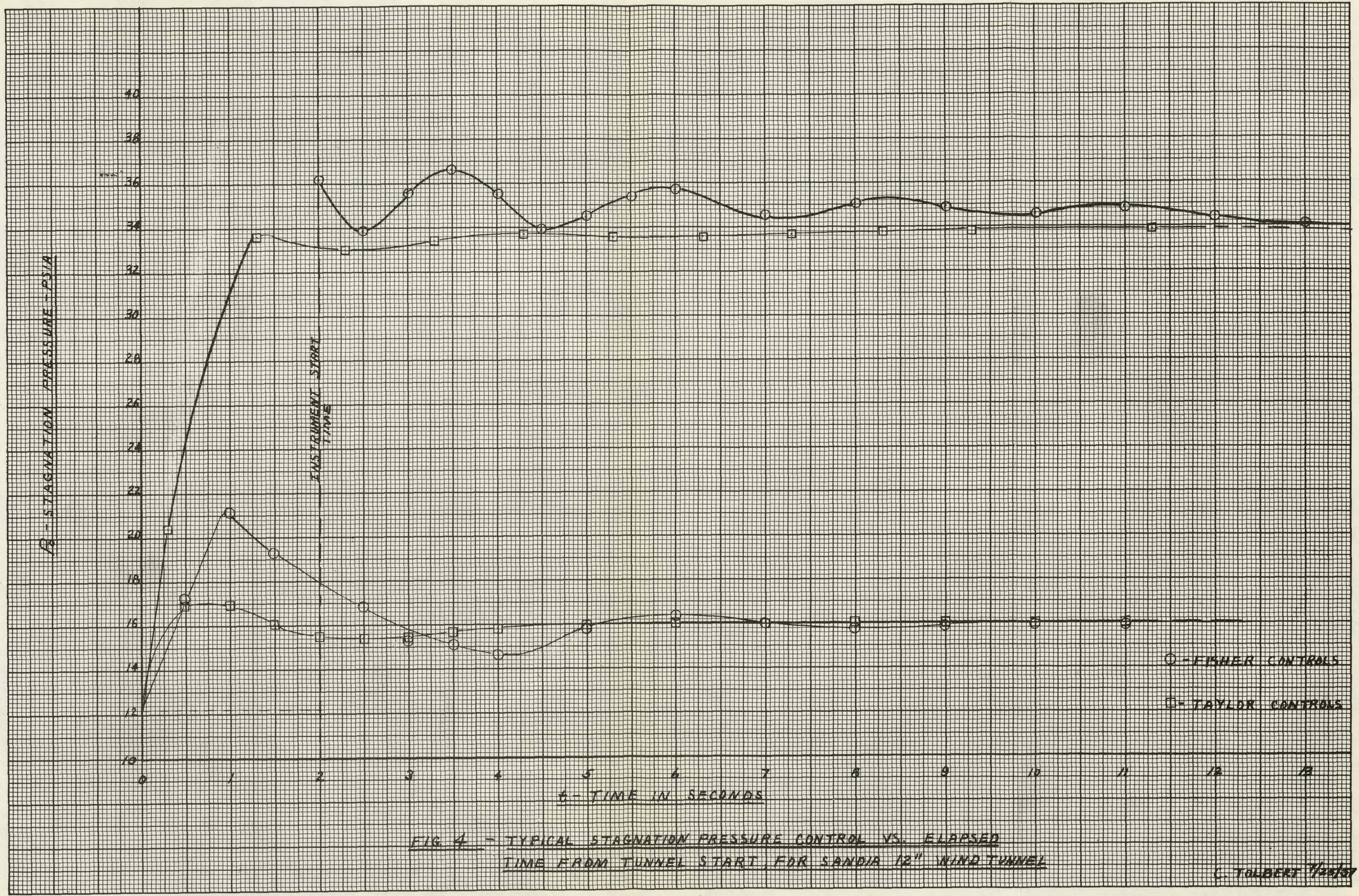


Issued by

Technical Information Division

Sandia Corporation

Albuquerque, New Mexico 